\title{
INCIDENCE OP INTERNAL ACCOUNTING AMONG OHIO COUNTRY GRAIN ELEVATORS
}

JOHN G. LABINE

and

CARL R. ZULAUF*

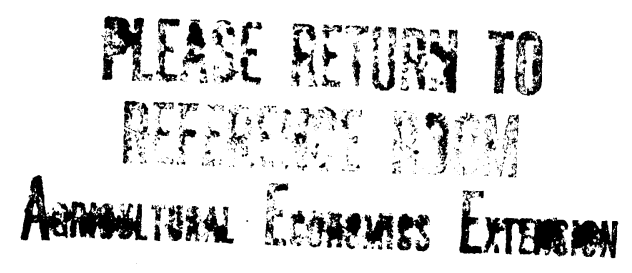

The authors thank Gary Schnitkey and Allan Lines for their assistance and comments on earlier drafts. Thanks are also extended to Pam Brown for editorial assistance.

\footnotetext{
*Former undergraduate student and current Assistant Professor, respectively, Department of Agricultural Economics and Rural Sociology, The Ohio State University.
} 


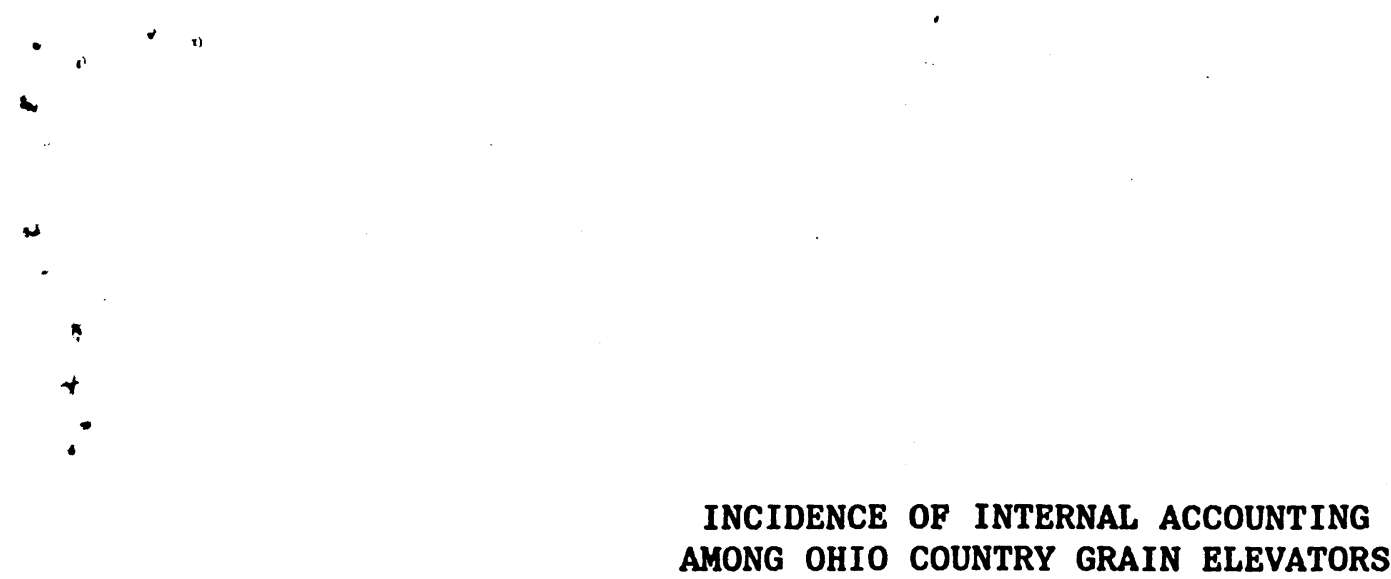


INCIDENCE OR INTERNAL ACCOUNTING
AMONG OHIO COUNTRY GRAIN ELEVATORS

\begin{abstract}
Internal accounting systems supply managers with cost, planning, evaluation, and control information not provided by traditional financial statements prepared according to Generally Accepted Accounting Principles. A conceptual model of factors associated with utilization of internal accounting systems was developed, and included size, use of computers for financial accounting, and managerial innovativeness. The model was tested using data collected from a survey of Ohio country elevators. Logistic multivariate analysis found use of internal accounting to be significantly associated with size and managerial innovativeness.
\end{abstract}

KEY WORDS: Internal Accounting, Country Elevators, Managerial Innovativeness 
Financial accounting is guided by Generally Accepted Accounting Principles (GAAP) as promulgated by the rule-making bodies of the American Institute of Certified Public Accountants (AICPA). The purpose of GAAP is to provide users of financial statements with relevant, reliable financial information prepared consistently from year to year, and comparably from firm to firm. In developing GAAP, the AICPA emphasizes the information needs of users external to the firm, such as investors, lenders, and regulatory agencies. Because of this emphasis, financial statements prepared in accordance with GAAP often fall short of providing managers of firms with information they need to adequately plan, evaluate, and control their business (1). This shortcoming has led managers to develop. internal accounting systems (IAS).

Internal accounting may be broadly defined as those accounting techniques and systems aimed at helping the collective decision making of management. As a result of the varying complexity and diversity of businesses, no standardized IAS exist. Each firm must develop a system that satisfies its unique requirements.

An example of the potential difference between the information provided by GAAP and internal accounting is the allocation of interest costs incurred in storing company owned grain. GAAP requires that such interest be expensed in the period in which the interest expense is incurred (2). This procedure reduces income during the period in which the interest is incurred, but inflates 
income in subsequent periods when the grain is sold. Economic reality (3), as well as accounting theory (4), suggest that expenses should be matched with the revenues they generate. A properly designed IAS can yield such a match, providing managers with more relevant, more comparable measures of income.

Objective of this study was to examine the relationship between use of IAS and various attributes of the firm and its management. A conceptual model of factors associated with utilization of internal accounting was developed, including firm size, use of computers for financial accounting, and level of managerial innovativeness. The model was tested using data collected from a survey of ohio country grain elevators. Logistic multivariate analysis found that size and managerial innovativeness were significantly related to use of IAS.

CONCEPTUAL MODEL OF FACTORS ASSOCIATED WITH USE OF INTERNAL ACCOUNTING

Use of internal accounting is hypothesized to be a function of several factors and can be expressed in the following functional form for firm i:

$$
Y_{i}=\beta\left(x_{i}\right)+\epsilon_{i}
$$

where:

$$
\begin{aligned}
& Y_{1}=\text { Use of internal accounting } \\
& x_{i}=\begin{array}{l}
\text { accounting } \\
\text { accou factors associated with use of internal }
\end{array} \\
& \beta_{i}=\text { a vector of estimated parameters } \\
& \epsilon_{i}=\text { random error term }
\end{aligned}
$$




\section{3}

Factors associated with the use of IAS include characteristics of both the firm and the firm's management. Size of the firm is hypothesized to be one such characteristic. As size increases, it is hypothesized that the probability a firm will develop an internal accounting system will also increase. Support for this hypothesis is two-fold. First, size of the firm has little effect on the costs of developing IAS. Therefore, cost of IAS per unit of output decreases as size increases. Second, Bruns and Kaplan found that, as organizations become more complex, more hierarchical, and more decentralized, the need for an effective IAS increases (5). Larger firms are more likely to exhibit these attributes, and thus more likely to need an IAS.

A second factor hypothesized to be associated with utilization of internal accounting is the ease of developing and implementing IAS. More specifically, use of a computer for financial accounting is hypothesized to be positively related to the use of IAS. Existence of a computer reduces the cost of collecting, processing, analyzing, and reporting information (6). Furthermore, internal accounting software can utilize data already collected by financial accounting software and can often run on existing hardware. Thus, firms using computers for financial accounting will likely find it more economical to develop internal accounting systems than firms that do not have computerized financial accounting.

A third hypothesized factor is the innovativeness of management. Innovative managers continually search for ways to maximize profits by increasing revenues and/or reducing costs. IAS 
provide a means of evaluating the costs of producing and marketing products and services, allowing managers to improve profitability through better cost control. Thus, managerial innovativeness and utilization of IAS are hypothesized to be positively related.

\section{DATA}

To collect data needed to test the model, a survey was mailed to managers of 265 Ohio country grain elevators during March 1988 . For purposes of this survey, a country grain elevator was defined as a firm primarily engaged in buying and selling grain, retailing agricultural inputs, and/or providing related services for farmers; and purchased the majority of its grain from farmers. The survey sample was obtained from the 1987 Directory of The Ohio Grain and Feed Association (OGFA) (7), a statewide trade organization whose members include 265 of the 347 country grain elevator firms licensed with the Ohio Department of Agriculture (8). The survey instrument was field tested before being mailed to the sample.

Managers returned 95 surveys, of which 21 were incomplete or otherwise unusable. The 74 usable surveys yielded a 28 percent response rate. Twenty percent of the respondents reported storage capacities of less than 150,000 bushels; 24 percent reported between 150,000 and 500,000 bushels; 20 percent, between 500,000 and $1,000,000$ bushels; 16 percent, between $1,000,000$ and $2,000,000$ bushels; and 19 percent, over 2,000,000 bushels. Comparison of respondents' storage capacities with those reported by the country elevators listed in the 1987 OGFA Directory revealed that larger 
elevators were over-represented among respondents. For example, only seven percent of the elevators listed in the Directory had storage capacities over 2,000,000 bushels.

Fifty-eight percent of the survey respondents were organized as cooperatives, 34 percent as corporations, and the remainder as proprietorships or partnerships (Table 1 ). Total volume handled in 1987 ranged from 64,000 bushels to $17,780,000$ bushels, with an average of $2,489,600$ bushels. The respondents varied widely concerning the share of total sales that was accounted for by grain sales. Over two-thirds of the respondents offered customers basis contracts, delayed price agreements, and storage, whereas fewer than half offered guaranteed minimum price contracts. Last, threequarters of the respondents indicated existence of a computer for financial accounting purposes.

Forty-three percent of survey respondents reported using IAS for purposes of evaluating and/or enhancing grain marketing efforts. Compared with firms that did not use internal accounting, firms using IAS were more likely to be cooperatives and to have multiple facilities, were nearly three times larger in terms of capacity and volume, and were more likely to offer customers each of the surveyed marketing options (Table 1).

\section{SELECTION OF ANALYTICAL TECHNIQUE}

Because use of internal accounting, the dependent variable in this analysis, is a binary variable, testing the conceptual model with least-squares regression will produce a heteroscedastic error 
term (9). Weighted least-squares can solve this problem, but the predicted value for the dependent variable may lie outside the binary range (9). A constraint can be placed on the estimated value of the dependent variable, but such a constraint might bias the estimated parameters (9). Thus, ordinary least-squares is not preferred on theoretical grounds.

Alternative analytical tools include linear discriminant analysis, probit, and logit. Both the probit and logit models, which are based on the cumulative normal probability and cumulative logistic probability functions respectively, are preferred over linear discriminant analysis whenever one of the independent variables is qualitative, as in this study (10). The probit and logit functions are similar, with the major difference being that, compared with the cumulative normal probability function, the cumulative logistic probability function has a slightly greater probability of values being in the tails of the distribution. Both the probit and logit models were estimated in this study. Similar to the results reported by Capps and Kramer (11), little difference was found between the results generated by these two statistical techniques. Therefore, only the logit results are presented.

\section{EMPIRICAL MODEL ESTIMATED}

The dependent variable was use of IAS to evaluate or enhance grain marketing efforts. It was a binary variable, and assigned a value of one if IAS was used or zero if IAS was not used. 
The independent variable, size, was measured as total bushel volume handled in 1987 . In addition to the size related arguments presented in the conceptual model section, the larger the volume of grain handled, the more likely inventory will be carried forward from one accounting year to the next. As previously discussed, this common business practice can result in a mismatch of revenues and expenses under GAAP. Internal accounting can address this problem.

The second independent variable, use of a computer for financial accounting, was measured as a binary variable. It was assigned a value of one if a computer was used or zero if a computer was not used.

Managerial innovativeness, the last independent variable, is a complex, multi-faceted variable that can be measured in many ways. Because the focus of the survey was on the use of IAS to evaluate or. enhance grain marketing efforts by country grain elevators, it was decided that a measure of grain marketing sophistication would be used as a proxy for managerial innovativeness. Guaranteed minimum price contracts are one of the most recently developed marketing options offered to customers by country grain elevators. They are a product of options on agricultural futures contracts, which began trading on the Chicago Board of Trade only in 1984 (12, pp. 10). Managers who offer the most recently developed marketing services are likely to do so in order to gain or maintain a leadership position in the local market, thereby improving or maintaining profitability. Managerial innovativeness was measured as a binary 
variable, being assigned a value of one if guaranteed minimum price contracts were offered or zero if these contracts were not offered.

The estimated parameters of the hypothesized variables were expected to be positive. That is, the probability of using IAS will increase with larger grain volume (i.e., size), with the use of computers for financial accounting, and with the offering of guaranteed minimum price contracts (i.e., the more innovative the management). The parameters were estimated using the SHAZAM statistical package.

\section{RESULTS}

The estimated coefficients for the size and managerial innovativeness variables had the hypothesized signs and were significantly different from zero at the 95 and 99 percent level of confidence, respectively (Table 2). In contrast, the estimated coefficient for use of a computer for financial accounting was not significantly different from zero at the 90 percent level of confidence. The model's chi-square indicated the model was statistically significant at the 99 level of confidence in explaining the use of IAS to evaluate or enhance grain marketing efforts. Last, the model correctly predicted the use (non-use) of IAS for 70 percent of the survey respondents.

The relative contribution of size and managerial innovativeness to explaining the probability of utilizing internal accounting can be evaluated by calculating the elasticity of using IAS. At the mean values of the respective variables, the elasticity for 
innovativeness was 0.42 , compared with 0.37 for size. These elasticities suggests that managerial innovativeness is relatively more important in determining the use of IAS, although the difference between the two significant variables is not large.

Lack of statistical significance for computers has two potential explanations. First, computers were widely used for financial accounting: by 64 percent of country elevator managers who did not use internal accounting and by 84 percent of country elevator managers who used internal accounting (Table 1). Thus, there may have been insufficient variation in the computer variable to allow a significant statistical relationship to be found. Second, the returns from IAS may be large enough that innovative managers will adopt it, regardless of the existence of a computer. Note, 12 percent of survey respondents who used internal accounting did not use a computer for financial accounting (Table 1).

\section{SUMMARY, CONCLUSIONS, AND IMPLICATIONS}

A conceptual model of factors associated with adoption of an internal accounting system was developed. It was tested using data collected from a survey of ohio country grain elevator managers. The fact that 43 percent of respondents to the survey had developed an internal accounting system to evaluate or enhance grain marketing efforts indicates that managers of grain elevators perceive a need for more and better accounting information than that being provided by traditional financial accounting systems. 
Logistic multivariate analysis of the conceptual model found support for the hypothesis that the probability of utilizing an internal accounting system increased as size of the firm increased, which in part represents increased need, and depended on the innovativeness of the firm's management in seeking new ways of Increasing profits. Further analysis suggested that managerial innovativeness was slightly more important than size in determining the use of internal accounting. Existence of a computer for financial accounting was not statistically related to use of internal accounting.

Because internal accounting systems are developed to meet the specific needs of management in a specific firm, it is necessary to study them in their actual organizational settings (6). This study has shown that field research of internal accounting is merited. Further examination of internal accounting may provide insights into the strengths and shortcomings of the financial performance of a wide variety of firms. 
REFERENCES

(1) Charles T. Horngren and George I. Foster. Cost Accounting: A Managerial Emphasis. 6th edition. Englewood Cliffs, NJ: Prentice-Hall, Inc. 1987.

(2) Financial Accounting Standards Board. Original Pronouncements, July 1973 -- June 1, 1987. Stamford: Financial Accounting Standards Board. 1987.

(3) Robert $N$. Anthony. Accounting for the cost of Interest. Lexington, Mass.: D.C. Heath and Company. 1975.

(4) Eldon S. Hendriksen. Accounting Theory. 4th edition. Homewood, IL: Richard D. Irwin, Inc. 1982.

(5) William J. Bruns, Jr. and Robert S. Kaplan, ed., Accounting \& Management: Field Study Perspectives. Boston: Harvard Business School Press. 1987.

(6) Thomas H. Johnson and Robert S. Kaplan. Relevance Lost: The Rise and Fall of Management Accounting. Boston: Harvard Business School Press. 1987.

(7) Ohio Grain and Feed Association. 1987 Industry Directory. 1987. 
(8) Donald Marsh. Administrative Assistant to Chief, Grain Warehouse Division, Ohio Department of Agriculture, Columbus, Ohio. Interview, 31 May, 1988.

(9) Robert S. Pindyck and Daniel L. Rubinfeld. Econometric Models and Economic Forecasts. 2nd edition. New York: McGraw-Hill Book Company. 1981.

(10) Max Halperin, William C. Blackwelder, and Joel I. Verter. "Estimation of the Multivariate Logistic Risk Function: Comparison of the Discriminant Function and Maximum Likelihood Approaches." Journal of Chronic Diseases. 24(1971):125-58.

(11) Oral Capps, Jr. and Randall A. Kramer. "Analysis of Food Stamp Participation Using Qualitative Choice Models." American Journal of Agricultural Economics. 67 (1985): 49-59.

(12) Commodity Futures Trading Commission. CFTC AgReport. Volume 5, Number 2. October 1984. 
Table 1. Summary of Country Grain Elevator Internal Accounting Survey, Ohio, 1988.

\begin{tabular}{|c|c|c|c|}
\hline Characteristic & $\begin{array}{c}\text { No } \\
\text { Internal } \\
\text { Accounting }\end{array}$ & $\begin{array}{c}\text { Internal } \\
\text { Accounting }\end{array}$ & Al1 \\
\hline Number of Responses & 42 & 32 & 74 \\
\hline \multicolumn{4}{|l|}{ Organized As: } \\
\hline Proprietorship or Partnership & $12 \%$ & $3 \%$ & $8 \%$ \\
\hline Corporation or S-Corporation & $38 \%$ & $28 \%$ & $34 \%$ \\
\hline Cooperative & $50 \%$ & $69 \%$ & $58 \%$ \\
\hline Total & $100 \%$ & $100 \%$ & $100 \%$ \\
\hline \multicolumn{4}{|l|}{ Structured As: } \\
\hline single, Independent Facility & $67 \%$ & $47 \%$ & $58 \%$ \\
\hline Multi-Facility Firm & $33 \%$ & $53 \%$ & $42 \%$ \\
\hline Total & $100 \%$ & $100 \%$ & $100 \%$ \\
\hline \multicolumn{4}{|l|}{ Average (1000 Bushels): } \\
\hline Capacity ${ }^{a}$ & 692 & 1,856 & 1,196 \\
\hline Volume Handled b & 1,397 & 3,924 & 2,490 \\
\hline \multicolumn{4}{|l|}{ Grain Sales Share of Total Sales: } \\
\hline $1-20 \%$ & $14 \%$ & $3 \%$ & $9 \%$ \\
\hline $21-40 \%$ & $19 \%$ & $6 \%$ & $13 \%$ \\
\hline $41-60 \%$ & $26 \%$ & $38 \%$ & $31 \%$ \\
\hline $61-80 \%$ & $29 \%$ & $22 \%$ & $26 \%$ \\
\hline $81-100 \%$ & $12 \%$ & $31 \%$ & $21 \%$ \\
\hline Total & $\overline{100 \%}$ & $100 \%$ & $100 \%$ \\
\hline \multicolumn{4}{|l|}{ Marketing Options offered: } \\
\hline Basis Contract & $55 \%$ & $84 \%$ & $68 \%$ \\
\hline Delayed Price Contract & $86 \%$ & $94 \%$ & $89 \%$ \\
\hline Storage & $83 \%$ & $94 \%$ & $88 \%$ \\
\hline Guaranteed Minimum Price Contract & $26 \%$ & $72 \%$ & $46 \%$ \\
\hline Warehouse Receipted Storage & $69 \%$ & $88 \%$ & $77 \%$ \\
\hline Used Futures to Hedge & & & \\
\hline Delayed Price Obligations & $40 \%$ & $63 \%$ & $50 \%$ \\
\hline $\begin{array}{l}\text { Used Computer for Financial } \\
\text { Accounting }\end{array}$ & $64 \%$ & $88 \%$ & $75 \%$ \\
\hline
\end{tabular}

a Measured in bushels of dry corn equivalent.

b Equals the sum of corn, oats, soybean, and wheat volume.

SOURCE: Original Survey 
Table 2. Logit Analysis of Pactors Associated With Use of Internal Accounting by Country Grain Elevators, Ohio, 1988.

Independent

Variables

Constant

Bushel Volume

Computer

Offered Guaranteed Minimum Price Contract

\section{Estimated} Coefficient

$-2.1365$

0.0026

0.6163

1.6106
Standard

Error

Summary Information:
Chi-Square
$23.6^{* *}$
Percent Right Predictions:
70.0

* Statistically Significant at $95 \%$ Confidence Level.

** Statistically Significant at $99 \%$ Confidence Level.

SOURCE: Computations on Original Data 